\title{
Individual and occupational risk factors for knee osteoarthritis: results of a case-control study in Germany
}

\author{
André Klussmann*1, Hansjürgen Gebhardt1', Matthias Nübling2, Falk Liebers³, Emilio Quirós Perea, Wolfgang Cordier ${ }^{4}$, \\ Lars V von Engelhardt ${ }^{5}$, Markus Schubert ${ }^{5}$, Andreas Dávid ${ }^{5}$, Bertil Bouillon ${ }^{6}$ and Monika A Rieger 7,8
}

\begin{abstract}
Introduction: A number of occupational risk factors are discussed in relation to the development and progress of knee joint diseases (for example, working in a kneeling or squatting posture, lifting and carrying heavy weights). Besides the occupational factors, a number of individual risk factors are important. The distinction between work-related and other factors is crucial in assessing the risk and in deriving preventive measures in occupational health.

Methods: In a case-control study, patients with and without symptomatic knee osteoarthritis (OA) were questioned by means of a standardised questionnaire complemented by a semi-standardised interview. Controls were matched and assigned to the cases by gender and age. Conditional logistic regression was used in analysing data.

Results: In total, 739 cases and 571 controls were included in the study. In women and men, several individual and occupational predictors for knee OA could be described: obesity (odds ratio (OR) up to 17.65 in women and up to 12.56 in men); kneeling/squatting (women, OR 2.52 (>8,934 hours/life); men, 2.16 (574 to 12,244 hours/life), 2.47 (>12,244 hours/life)); genetic predisposition (women, OR 2.17; men, OR 2.37); and sports with a risk of unapparent trauma (women, OR 2.47 ( $\geq 1,440$ hours/life); men, 2.58 ( $\geq 3,232$ hours/life)). In women, malalignment of the knee (OR 11.54), pain in the knee already in childhood (OR 2.08), and the daily lifting and carrying of loads ( $\geq 1,088$ tons/life, OR 2.13) were related to an increased OR; sitting and smoking led to a reduced OR.
\end{abstract}

Conclusions: The results support a dose-response relationship between kneeling/squatting and symptomatic knee $\mathrm{OA}$ in men and, for the first time, in women. The results concerning general and occupational predictors for knee OA reflect the findings from the literature quite well. Yet occupational risks such as jumping or climbing stairs/ladders, as discussed in the literature, did not correlate with symptomatic knee OA in the present study. With regards to occupational health, prevention measures should focus on the reduction of kneeling activities and the lifting and carrying of loads as well as general risk factors, most notably the reduction of obesity. More intervention studies of the effectiveness of tools and working methods for reducing knee straining activities are needed.

\section{Introduction Background}

Suffering from musculoskeletal diseases or disorders is the most frequent reason for absence from work in the western world. The inability to work as a consequence of diseases or disorders of the musculoskeletal system and the connective tissue resulted in $\mathbf{1 0 3 . 6}$ million days of

\footnotetext{
*Correspondence: klussmann@uni-wuppertal.de

1 Institute of Occupational Health, Safety and Ergonomics (ASER) at the University of Wuppertal, Corneliusstraße 31, 42329 Wuppertal, Germany Full list of author information is available at the end of the article
}

absence (23.7\% of all days of absence) in Germany in 2007. This led to a loss in the gross domestic product of $€ 17.3$ billion [1]. One of the frequent impairing disorders of the musculoskeletal system is knee osteoarthritis (OA).

The central pathologic features of OA are the loss of hyaline articular cartilage and changes in the subchondral bone. A number of occupational and nonoccupational risk factors are related to the development and progress of knee OA, with the proportion of radiographic knee OA in men due to job activities reaching 15 to 30\% [2]. For reviews on risk factors with different focuses, see [3-11]. 
Most of the existing studies focus on exercise through sports, individual factors, genetic factors, or occupational factors. Studies including comprehensive data and analysis are rare. The distinction between work-related and other factors is crucial in assessing risk and in deriving preventive measures in occupational health.

\section{Aim of the study}

The aim of the research project ArGon - an acronym for Arbeitsbedingungen (working conditions) and Gonarthrose (knee OA) - was to find the most parsimonious model considering different occupational factors (for example, kneeling and squatting activities, the lifting and carrying of loads, standing, jumping) and other influencing factors (for example, age, gender, constitutional factors, sports) to predict the occurrence of symptomatic knee OA in Germany.

\section{Materials and methods Study design}

The present case-control study was based on the populations of two neighbouring regions in Germany. The hospitals involved in the study are university teaching hospitals. The hospitals were chosen to include a balanced and representative town-country relationship. The urban and rural infrastructure includes a wide range of industrial workers, craftspeople, office workers, managers as well as farmers in the countryside. Cases were recruited from the surgical-orthopaedic wards and from appropriate outpatient clinics; controls were recruited from the accident surgery services of three participating hospitals and were matched with the case group according to age and place of residence.

Both groups filled out a standardised questionnaire, and a standardised patient record was filled out by an orthopaedic surgeon (cases only). In addition, participants with jobs involving lifting and carrying of loads were interviewed. Besides the consecutive recruitment in the hospitals, patients who could not be addressed directly during their hospitalisation were contacted retroactively by the hospital physician. All questionnaires were collected and evaluated in the study centre.

\section{Instruments}

\section{Standardised questionnaire}

The questionnaire was developed on the results of a literature review [12]. Previous literature (in English and German) was analysed, and relevant risk factors and confounding factors were included in the questionnaire. Hence the questionnaire contained questions about sociodemographic factors, relevant diseases, occupational history, and leisure-time activities. Participants were asked to describe every occupation, every sport, and every other leisure-time activity, and they were asked to indicate the respective duration (in years) and also the number of hours per day and per week. In the work analysis, the amount of different body postures (sitting, standing, walking, kneeling/squatting) as well as the prevalence of certain job characteristics (for example, climbing stairs, jumping, lifting/carrying of loads, time pressure) was assessed.

\section{Partially standardised telephone interview}

The telephone interview contained detailed questions on the frequency and duration of lifting and carrying for every occupational employment. This interview was conducted if daily lifting or carrying of loads was mentioned in the questionnaire by cases or controls in order to obtain more detailed information about the individual's work tasks.

\section{Patient record}

The patients' history and the physicians' findings were documented in a patient record including information on general health status, as well as the condition of knee cartilage, meniscus, and ligaments (according to the International Cartilage Repair Society standard). This patient record was filled out by the orthopaedic surgeon treating the patient (cases only).

\section{Recruitment and inclusion criteria of cases and controls General inclusion criteria}

The inclusion criteria were as follows: age between 25 and 75 years, place of residence in the defined vicinity of the participating hospitals, and linguistic and cognitive ability to understand and fill out the questionnaire and to provide informed consent.

\section{Additional criteria for the case group}

The case group's additional criteria were as follows: knee OA confirmed by either radiological diagnostics ( $\geq$ grade II on the Kellgren and Lawrence scale [13]) or findings from arthroscopy or open surgery ( $\geq$ grade III on the Outerbridge scale [14]). Further criteria for inclusion were: diagnosis of knee OA for no longer than 10 years; no previous fractures involving knee joints or injuries of the knee (ligament or cartilage injuries); and no inflammatory or reactive knee joint illnesses.

\section{Additional criteria for the control group}

The control group's additional criteria were as follows: treatment for an accident due to an external cause (that is, not due to circulatory, metabolic, or neurological disorders), an accident that was not work-related, and no already existing physician diagnosis of knee OA.

\section{Power of the dataset}

Before recruitment, the power of the dataset was estimated with 800 cases and an equal number of controls using EpiManager software [15]. The distribution was thereby assumed to be approximately $60 \%$ women and $40 \%$ men. 
The estimated number of participants could not be achieved within the 24-month period, although finally 739 cases (including 438 females) and 571 controls (including 303 females) could be included. Assuming a prevalence of $10 \%$ for kneeling/squatting activities in the population, a significantly higher prevalence (odds ratio $(\mathrm{OR})>2$ ) would be detected with a power of approximately $80 \%$ in men and $88 \%$ in women if there were no confounding factors.

\section{Analysis}

In the first step, cumulative calculation of life doses was determined over all practiced activities and occupations (hours/life, tons/life, or frequency/life). Smoking was summarised in package-years (1 package-year $=$ smoking 20 cigarettes/day for 1 year). The retrospective observation period for the cases ended at the time at which the diagnosis of knee OA was first made. The time difference between the time of inclusion in the study and the time of diagnosis of knee OA for the first time was calculated for all cases. In the controls, the median of this period ( 3 years) was subtracted from the time point of inclusion in the study in order to calculate the comparable exposure period in the controls.

In total, 180 items (183 in women) derived from the literature were generated (occupational factors, 19 items; sports, 91 items; leisure-time activities, 19 items; medical history, 29 items; individual factors, 22 items (25 in women)).

In the next step, all items were checked for correlation with the outcome (symptomatic knee OA) in bivariate analysis separately for men and women using logistic regression. As most sport activities showed a low prevalence, orthopaedic and accident surgeons as well as a sport physician were asked to group the single activities into categories (for example, activities suitable for prevention of knee OA, activities with impact force on the knee joint, activities with risk for unapparent trauma of the tibiofemoral joint). All of these groups were also correlated separately with the outcome. The strongest correlation was between the outcome and the group of sports with risk for unapparent trauma (in hours/life). This group was used for further analysis.

All items correlating with $P<0.2$ were selected for further analysis. This procedure was based on the references of Hosmer and Lemeshow [16]. Thirty-six items in men and 39 items in women were found to be in significant association with the outcome (men/women: occupational factors, 16 items/10 items; leisure-time activities, 2 items/3 items; medical history, 12 items/17 items; individual factors, 5 items/7 items; and sports with risk for unapparent trauma, 1 item/1 item). These items were taken into the final multivariable model aimed at describing the most parsimonious model for the occurrence of symptomatic knee OA in Germany (separately for men and women).

In the next step, to form the final model, constant items were transformed into categorical variables for better representation. A further reason for the transformation into categorical variables was the fact that the metric parameters only rarely showed a normal distribution. With the categorisation of the cumulative life doses, the zero group (no exposure at all) was defined as a separate category; the remaining values were then divided into two groups (median split) or into three groups (tertile split), depending upon the remaining group size. The body mass index (BMI) was categorised into the groups of normal weight $\left(\mathrm{BMI}=18.5\right.$ to $\left.<25 \mathrm{~kg} / \mathrm{m}^{2}\right)$, overweight $\left(\mathrm{BMI} \geq 25\right.$ to $<30 \mathrm{~kg} / \mathrm{m}^{2}$ ), obesity grade $\mathrm{I}$ (BMI $\geq 30$ to $<35$ $\mathrm{kg} / \mathrm{m}^{2}$ ), obesity grade II (BMI $\geq 35$ to $<40 \mathrm{~kg} / \mathrm{m}^{2}$ ), and obesity grade III (BMI $\geq 40 \mathrm{~kg} / \mathrm{m}^{2}$ ) according to the definitions of the World Health Organization [17]. Among men, the two groups obesity grade II and obesity grade III were merged, since the number of men was very small with regard to obesity grade III. These categorised groups of exposure were compared in each case with the zeroexposure group.

Owing to an unequal distribution of the age between cases and controls, age-stratified evaluations (five age groups) were carried out. The models were computed with conditional logistic regression using SAS 9.2 (SAS Institute Inc, North Carolina, USA). The most parsimonious models (only significant predictors enclosed, $P \leq$ 0.05 ) for men and women were calculated (successive slimming).

\section{Ethics}

The study protocol [12] was approved by the Ethical Committee of the University Witten/Herdecke (approval number 61/2006). The ethical aspects were in full agreement with the Helsinki Declaration as well as the German Federal Data Protection Act.

\section{Results}

\section{Description of the sample}

In the 24-month recruitment period 2,251 potential cases and 2,780 potential controls were analysed, from which 739 cases and 571 controls could be included in the study (Figure 1). The distribution of the included cases and controls is presented in Table 1.

\section{Results of exposure assessment}

The proportion of exposed and nonexposed subjects among cases and controls with regard to occupational exposures are presented in Table 2.

The prevalence of sports and leisure-time activities was somewhat equal within cases and controls. Some of the interviewees could not remember the amount and the 


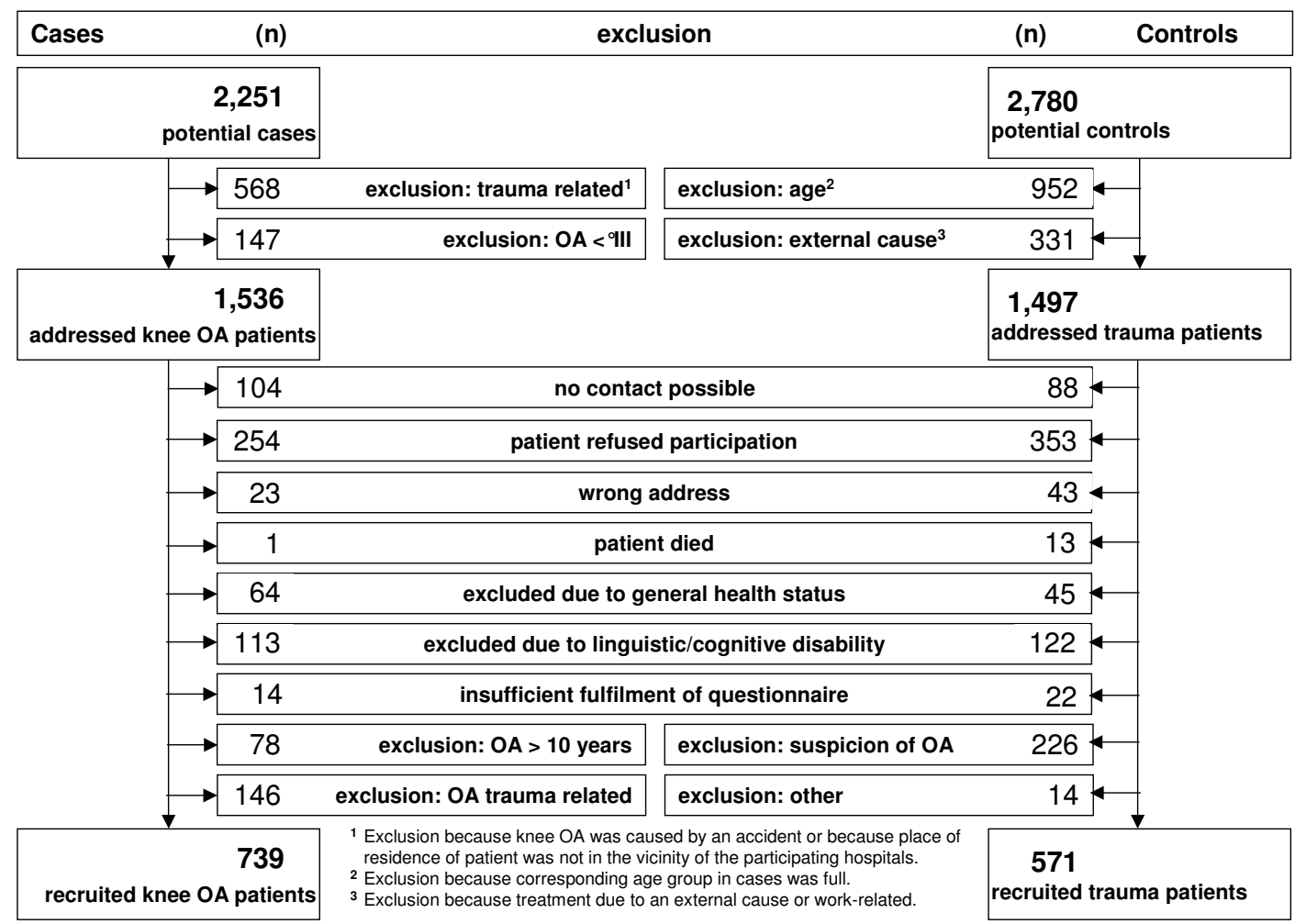

Figure 1 Recruitment of cases and controls. OA, osteoarthritis.

duration of their activities. Interviewees with and without specifications on the amount and duration of activities are therefore described separately in Table 3.

Cumulative exposures were calculated for use in logistic regression analysis. For this calculation, only the exposures of the interviewee who could remember the amount and the duration of their activities were taken into account. Missing values were extracted into a separate group (Table 4).

\section{Predictors of symptomatic knee OA: models}

In women, 39 items correlated with the outcome in the bivariate analysis. Based on these outcomes, the most parsimonious model for women was calculated with conditional logistic regression (Table 5). This model contains the variables pain in the knee during childhood, knee OA in close relatives (parents, brother, or sister), malalignment of the tibiofemoral joint, BMI, cumulative kneeling or squatting (in hours/live), smoking (in package-years),

\section{Table 1: Distribution of cases and controls}

Age at inclusion in study (years) Age used for exposure analysis (years)

\begin{tabular}{|c|c|c|c|c|c|}
\hline Gender & $n$ & Mean & $\begin{array}{l}\text { Standard } \\
\text { deviation }\end{array}$ & Mean & $\begin{array}{l}\text { Standard } \\
\text { deviation }\end{array}$ \\
\hline Female & 438 & 62.0 & 9.6 & 59.6 & 9.8 \\
\hline Male & 301 & 60.0 & 11.1 & 57.1 & 11.2 \\
\hline Female & 303 & 57.8 & 11.8 & 54.8 & 11.8 \\
\hline Male & 268 & 53.9 & 12.7 & 50.9 & 12.7 \\
\hline
\end{tabular}


Table 2: Occupational exposure to knee-straining activities: proportion of exposed and nonexposed subjects among cases and controls

\begin{tabular}{|c|c|c|c|c|c|c|c|c|}
\hline \multirow[b]{2}{*}{ Exposure } & \multirow[b]{2}{*}{ Gender } & \multirow[b]{2}{*}{$\begin{array}{l}\text { Controls/ } \\
\text { cases }\end{array}$} & \multicolumn{2}{|c|}{ Exposed } & \multicolumn{2}{|c|}{ Not exposed } & \multicolumn{2}{|c|}{ No indication } \\
\hline & & & $n$ & $\%$ & $n$ & $\%$ & $n$ & $\%$ \\
\hline \multirow[t]{4}{*}{ Sitting } & Female & Controls & 261 & 86.2 & 28 & 9.2 & 14 & 4.6 \\
\hline & & Cases & 367 & 83.8 & 60 & 13.7 & 11 & 2.5 \\
\hline & Male & Controls & 228 & 85.1 & 34 & 12.7 & 6 & 2.2 \\
\hline & & Cases & 239 & 79.4 & 53 & 17.6 & 9 & 3.0 \\
\hline \multirow[t]{4}{*}{ Standing } & Female & Controls & 240 & 79.2 & 49 & 16.2 & 14 & 4.6 \\
\hline & & Cases & 363 & 82.9 & 64 & 14.6 & 11 & 2.5 \\
\hline & Male & Controls & 226 & 84.4 & 36 & 13.4 & 6 & 2.2 \\
\hline & & Cases & 249 & 82.7 & 43 & 14.3 & 9 & 3.0 \\
\hline \multirow[t]{4}{*}{ Walking } & Female & Controls & 249 & 82.2 & 40 & 13.2 & 14 & 4.6 \\
\hline & & Cases & 381 & 87.0 & 46 & 10.5 & 11 & 2.5 \\
\hline & Male & Controls & 241 & 90.0 & 21 & 7.8 & 6 & 2.2 \\
\hline & & Cases & 266 & 88.4 & 26 & 8.6 & 9 & 3.0 \\
\hline \multirow{4}{*}{$\begin{array}{l}\text { Kneeling, } \\
\text { squatting }\end{array}$} & Female & Controls & 113 & 37.3 & 176 & 58.1 & 14 & 4.6 \\
\hline & & Cases & 215 & 49.1 & 212 & 48.4 & 11 & 2.5 \\
\hline & Male & Controls & 118 & 44.1 & 144 & 53.7 & 6 & 2.2 \\
\hline & & Cases & 163 & 54.5 & 129 & 42.5 & 9 & 3.0 \\
\hline \multirow{4}{*}{$\begin{array}{l}\text { Climbing } \\
\text { stairs }\end{array}$} & Female & Controls & 186 & 61.4 & 104 & 34.3 & 13 & 4.3 \\
\hline & & Cases & 317 & 72.4 & 111 & 25.3 & 10 & 2.3 \\
\hline & Male & Controls & 181 & 67.6 & 81 & 30.2 & 6 & 2.2 \\
\hline & & Cases & 220 & 73.1 & 75 & 24.9 & 6 & 2.0 \\
\hline \multirow[t]{4}{*}{ Jumping } & Female & Controls & 46 & 15.3 & 244 & 80.5 & 13 & 4.2 \\
\hline & & Cases & 91 & 20.8 & 337 & 76.9 & 10 & 2.3 \\
\hline & Male & Controls & 79 & 29.5 & 183 & 68.3 & 6 & 2.2 \\
\hline & & Cases & 120 & 39.8 & 173 & 57.5 & 8 & 2.7 \\
\hline \multirow{4}{*}{$\begin{array}{l}\text { Lifting/ } \\
\text { carrying } \\
\text { of loads }\end{array}$} & Female & Controls & 101 & 32.0 & 144 & 47.5 & 62 & 20.5 \\
\hline & & Cases & 152 & 35.7 & 190 & 43.4 & 96 & 21.9 \\
\hline & Male & Controls & 162 & 60.4 & 87 & 32.5 & 19 & 7.1 \\
\hline & & Cases & 196 & 65.1 & 83 & 27.6 & 22 & 7.3 \\
\hline
\end{tabular}

cumulative sitting (in hours/life), cumulative daily lifting and carrying (in tons/life), and cumulative sports with risk of unapparent trauma (in hours/life). Beside the occupational exposure, the data for sitting and kneeling or squatting also include housework activities. The reference categories were set to an OR of 1 . In the further categories of the variables, the OR is compared with the respective reference category.
The highest OR was calculated with rising BMI. Compared with those female participants with normal weight, women with obesity grade I had a higher risk of suffering from symptomatic knee OA (OR, 3.5; 95\% confidence interval (CI), 2.1 to 5.9), as did the group of women with obesity grade II (OR, 11.6; 95\% CI, 4.4 to 30.6) and women with obesity grade III (OR, 17.6; 95\% CI, 4.5 to $69.2)$ in particular. The presence of a malalignment of the 


\begin{tabular}{|c|c|c|c|c|c|c|c|}
\hline \multirow[b]{2}{*}{ Gender } & \multirow[b]{2}{*}{ Exposure } & \multicolumn{2}{|c|}{ Controls } & \multicolumn{2}{|c|}{ Cases } & \multicolumn{2}{|c|}{ Total } \\
\hline & & $n$ & $\%$ & $n$ & $\%$ & $n$ & $\%$ \\
\hline \multirow[t]{3}{*}{ Female } & No sports & 94 & 31.0 & 143 & 32.6 & 237 & 32.0 \\
\hline & $\begin{array}{l}\text { Sports - cumulative exposure could be } \\
\text { calculated }\end{array}$ & 170 & 56.1 & 237 & 54.1 & 407 & 54.9 \\
\hline & $\begin{array}{l}\text { Sports - no cumulative exposure could be } \\
\text { calculated }\end{array}$ & 39 & 12.9 & 58 & 13.2 & 97 & 13.1 \\
\hline \multirow[t]{3}{*}{ Male } & No sports & 41 & 15.3 & 39 & 13.0 & 80 & 14.1 \\
\hline & $\begin{array}{l}\text { Sports - cumulative exposure could be } \\
\text { calculated }\end{array}$ & 201 & 75.0 & 241 & 80.1 & 442 & 77.7 \\
\hline & $\begin{array}{l}\text { Sports - no cumulative exposure could be } \\
\text { calculated }\end{array}$ & 26 & 9.7 & 21 & 7.0 & 47 & 8.3 \\
\hline \multirow[t]{3}{*}{ Female } & No leisure time activities & 173 & 57.1 & 239 & 54.6 & 412 & 55.6 \\
\hline & $\begin{array}{l}\text { Leisure time activities - cumulative exposure } \\
\text { could be calculated }\end{array}$ & 97 & 32.0 & 169 & 38.6 & 266 & 35.9 \\
\hline & $\begin{array}{l}\text { Leisure time activities - no cumulative } \\
\text { exposure could be calculated }\end{array}$ & 33 & 10.9 & 30 & 6.8 & 63 & 8.5 \\
\hline \multirow[t]{3}{*}{ Male } & No leisure time activities & 154 & 57.5 & 154 & 51.2 & 308 & 54.1 \\
\hline & $\begin{array}{l}\text { Leisure time activities - cumulative exposure } \\
\text { could be calculated }\end{array}$ & 90 & 33.6 & 130 & 43.2 & 220 & 38.7 \\
\hline & $\begin{array}{l}\text { Leisure time activities - no cumulative } \\
\text { exposure could be calculated }\end{array}$ & 24 & 9.0 & 17 & 5.6 & 41 & 7.2 \\
\hline
\end{tabular}

tibiofemoral joint was also associated with symptomatic knee OA (OR, 11.5; 95\% CI, 4.7 to 28.7) in women. Within the physical loads, cumulative kneeling and squatting $>8,934$ hours over life increased the risk of symptomatic knee OA (OR, 2.5; 95\% CI, 1.4 to 4.7). Cumulative daily lifting and carrying $\geq 1,088$ tons over life resulted in an OR of 2.1 (95\% CI, 1.1 to 4.0). Further risk factors for the development of symptomatic knee OA are genetic predisposition (knee OA in parents, brother or sister: OR, 2.2; 95\% CI, 1.4 to 3.4 ), pain in the knee as a child (OR, 2.1; 95\% CI, 1.0 to 4.3), and the practice of injury-prone types of sport with an extent of $\geq 1,440$ hours over life (OR, 2.5; 95\% CI, 1.3 to 4.6). A decreasing effect was calculated for smoking ( $>20$ package-years: OR, 0.4; 95\% CI, 0.3 to 0.7 ) and cumulative sitting (OR, 0.5 ; $95 \%$ CI, 0.3 to 1.0 ) for 16,032 to 33,119 hours over life, and for $>33,119$ hours over life (OR, 0.4 ; $95 \% \mathrm{CI}, 0.2$ to $0.8)$.

In men, 36 items correlated with the outcome in bivariate analysis. Based on these outcomes, the most parsimonious model for men was calculated with conditional logistic regression (Table 6). This model contains the variables knee OA in close relatives (parents, brother, or sister), BMI, cumulative kneeling or squatting (in hours/ life), and cumulative sports with risk for unapparent trauma (hours/life).
Similar to the women, the highest OR appeared with rising BMI in men. Compared with those male participants with normal weight, men with obesity grade I had a higher risk of suffering from symptomatic knee OA (OR, $4.0 ; 95 \% \mathrm{CI}, 2.3$ to 6.9 ), as did men with obesity grade II or obesity grade III (BMI $\geq 35 \mathrm{~kg} / \mathrm{m}^{2}$ : OR, 12.6 ; $95 \% \mathrm{CI}, 4.4$ to 35.9). Within the physical loads, cumulative kneeling and squatting for 3,574 to 12,244 hours over life led to an increased risk to suffer from symptomatic knee OA (OR, 2.2; $95 \% \mathrm{CI}, 1.2$ to 3.8 ). The risk increased even further when cumulative kneeling or carrying was $>12,244$ hours (OR, 2.5; 95\% CI, 1.4 to 4.3). Lifting and carrying as well as pulling and pushing of loads did not result as a predictor for symptomatic knee OA in men. Further factors of risk were the genetic predisposition (knee OA with parents, brother, or sister: OR, 2.4; 95\% CI, 1.4 to 4.0 ) and the practice of injury-prone sports $\geq 3,232$ hours (OR, 2.5; 95\% CI, 1.6 to 4.2 )

\section{Discussion}

\section{Symptomatic knee OA and occupational factors} Symptomatic knee OA and kneeling/squatting

In the present study, an OR of 2.5 (95\% CI, 1.4 to 4.7) for accumulated kneeling and squatting $>8,934$ hours over life in women was calculated. In men, the OR for kneeling/squatting for 3,474 to 12,244 hours over life was 2.2 
(95\% CI, 1.2 to 3.8), and the OR for kneeling/squatting for $>12,244$ hours over life was 2.5 (95\% CI, 1.4 to 4.3 ). These results indicate an effect of kneeling/squatting on the occurrence of symptomatic knee OA in both genders.

In 2005 Jensen calculated an individual exposure from the amount of knee-straining activities and the number of years in the trade within a collective of floor layers, carpenters and compositors. The ORs for knee complaints and radiographically determined knee OA were 3.0 (95\% CI, 0.5 to 17.2$)$ in the low-exposure group, $4.2(95 \% \mathrm{CI}$, 0.6 to 27.6 ) in the medium-exposure group, and 4.9 (95\% CI, 1.1 to 21.9) in the high-exposure group compared with the zero-exposure group [18]. D'Souza and colleagues reported on an analysis of the US national survey (Third National Health and Nutrition Examination Survey (NHANES III)) and used ergonomists' ratings of job categories to describe relationships between work activities and symptomatic knee OA [19]. A significant exposure-response relationship was found between symptomatic knee OA and kneeling in men but not in women. Within a German case-control study, the OR of having radiographically confirmed knee OA was $2.4(95 \%$
CI, 1.1 to 5.0) within the group with cumulative exposure to kneeling and squatting $>10,800$ hours compared with unexposed subjects [20].

To our knowledge, only one study investigating the dose-response relationship of cumulative kneeling or squatting and knee OA found no correlation [21]. In this study, however, the daily exposures of kneeling and squatting were asked dichotomously ( $>1$ hour/day or $\leq 1$ hour/ day) and then multiplied by exposure years, so these results might be imprecise.

In sum, our results support the presumptions that there is a dose-response relationship between knee-straining work activities and symptomatic knee OA, and that this relationship exists also in women.

\section{Symptomatic knee $O A$ and lifting and carrying of loads}

In the present study, an OR of 2.1 (95\% CI, 1.1 to 4.0 ) could be derived in women for lifting and carrying of least 1,088 tons over life. This correlation was not significant in men.

In the study by D'Souza and colleagues mentioned above, a significant trend in heavy lifting and severe symptomatic knee OA was detected in both genders [19].

Table 4: Categorisation of the cumulative life doses

\section{Tertile split}

\begin{tabular}{lll}
\hline First tertile & Second tertile & Third tertile
\end{tabular}

\begin{tabular}{|c|c|c|c|}
\hline \multicolumn{4}{|c|}{ Smoking (package-years) } \\
\hline Female & $<9$ & 9 to 20 & $>20$ \\
\hline Male & $<16.5$ & 16.5 to 27 & $>27$ \\
\hline \multicolumn{4}{|c|}{ Kneeling/squatting (hours/life) } \\
\hline Female & $<3,542$ & 3,542 to 8,934 & $>8,934$ \\
\hline Male & $<3,573$ & 3,573 to 12,243 & $>12,243$ \\
\hline \multicolumn{4}{|c|}{ Sitting (hours/life) } \\
\hline Female & $<16,031$ & 16,031 to 33,119 & $>33,119$ \\
\hline \multirow[t]{3}{*}{ Male } & $<15,180$ & 15,180 to 34,960 & $>34,960$ \\
\hline & \multicolumn{2}{|c|}{ Median split } & \\
\hline & Low exposure & High exposure & \\
\hline \multicolumn{4}{|c|}{ Lifting and carrying (tons/life) } \\
\hline Female & $<1,088$ & $\geq 1,088$ & \\
\hline Male & $<2,214$ & $\geq 2,214$ & \\
\hline \multicolumn{4}{|c|}{$\begin{array}{l}\text { Sports with risk for unapparent } \\
\text { trauma (hours/life) }\end{array}$} \\
\hline Female & $<1,440$ & $\geq 1,440$ & \\
\hline Male & $<3,232$ & $\geq 3,232$ & \\
\hline
\end{tabular}


Table 5: Conditional logistic regression model for women: most parsimonious model

\begin{tabular}{|c|c|c|c|c|c|c|c|}
\hline & Item & $n_{\text {tot }}$ & Cases (n) & Controls $(n)$ & $\begin{array}{l}P \\
\text { value }\end{array}$ & Odds ratio & $\begin{array}{l}95 \% \\
\text { confidence } \\
\text { interval }\end{array}$ \\
\hline \multirow{2}{*}{$\begin{array}{l}\text { Knee pain } \\
\text { during } \\
\text { childhood }\end{array}$} & No (R) & 623 & 361 & 262 & & 1.00 & - \\
\hline & Yes & 59 & 41 & 18 & $<0.05$ & 2.08 & 1.01 to 4.26 \\
\hline \multirow{2}{*}{$\begin{array}{l}\text { Knee } O A \text { in } \\
\text { relatives }\end{array}$} & No (R) & 408 & 216 & 192 & & 1.00 & - \\
\hline & Yes & 205 & 142 & 63 & $<0.001$ & 2.17 & 1.40 to 3.37 \\
\hline \multirow{2}{*}{$\begin{array}{l}\text { Malalignmen } \\
\text { t of the knee }\end{array}$} & No (R) & 624 & 336 & 288 & & 1.00 & - \\
\hline & Yes & 90 & 83 & 7 & $<0.001$ & 11.54 & 4.65 to 28.66 \\
\hline \multirow{5}{*}{$\begin{array}{l}\text { Body mass } \\
\text { index }\end{array}$} & 18.5 to $<25 \mathrm{~kg} / \mathrm{m}^{2}(\mathrm{R})$ & 255 & 97 & 158 & & 1.00 & - \\
\hline & $\geq 25$ to $<30 \mathrm{~kg} / \mathrm{m}^{2}$ & 249 & 163 & 86 & $<0.001$ & 3.21 & 2.09 to 4.96 \\
\hline & $\geq 30$ to $<35 \mathrm{~kg} / \mathrm{m}^{2}$ & 149 & 107 & 42 & $<0.001$ & 3.55 & 2.12 to 5.94 \\
\hline & $\geq 35$ to $<40 \mathrm{~kg} / \mathrm{m}^{2}$ & 55 & 49 & 6 & $<0.001$ & 11.58 & 4.38 to 30.63 \\
\hline & $\geq 40 \mathrm{~kg} / \mathrm{m}^{2}$ & 23 & 20 & 3 & $<0.001$ & 17.65 & 4.50 to 69.23 \\
\hline \multirow[t]{4}{*}{ Smoking } & No (R) & 391 & 255 & 136 & & 1.00 & - \\
\hline & Yes, <9 package-years & 117 & 63 & 54 & NS & 0.69 & 0.40 to 1.17 \\
\hline & Yes, 9 to 20 package-years & 114 & 64 & 50 & NS & 1.16 & 0.67 to 2.03 \\
\hline & Yes, >20 package-years & 115 & 54 & 61 & $<0.01$ & 0.43 & 0.26 to 0.73 \\
\hline \multirow{4}{*}{$\begin{array}{l}\text { Occupation: } \\
\text { kneeling or } \\
\text { squatting }\end{array}$} & No (R) & 388 & 212 & 176 & & 1.00 & - \\
\hline & Yes, $<3,542$ hours/life & 109 & 62 & 47 & NS & 1.50 & 0.83 to 2.69 \\
\hline & Yes, 3,542 to 8,934 hours/life & 110 & 68 & 42 & NS & 1.36 & 0.78 to 2.37 \\
\hline & Yes, $>8,934$ hours/life & 109 & 85 & 24 & $<0.01$ & 2.52 & 1.35 to 4.68 \\
\hline \multirow{4}{*}{$\begin{array}{l}\text { Occupation: } \\
\text { sitting }\end{array}$} & No $(R)$ & 88 & 60 & 28 & & 1.00 & - \\
\hline & Yes, $<16,032$ hours/life & 209 & 127 & 82 & NS & 0.72 & 0.37 to 1.40 \\
\hline & $\begin{array}{l}\text { Yes, } 16,032 \text { to } 33,119 \text { hours/ } \\
\text { life }\end{array}$ & 209 & 122 & 87 & $<0.05$ & 0.51 & 0.26 to 0.99 \\
\hline & Yes, $>33,119$ hours/life & 210 & 118 & 92 & $<0.01$ & 0.39 & 0.20 to 0.76 \\
\hline \multirow{4}{*}{$\begin{array}{l}\text { Occupation: } \\
\text { lifting and } \\
\text { carrying }\end{array}$} & No (R) & 263 & 139 & 124 & & 1.00 & - \\
\hline & sometimes & 65 & 37 & 28 & NS & 0.88 & 0.44 to 1.77 \\
\hline & Yes, $<1,088$ tons/life & 122 & 69 & 53 & NS & 0.69 & 0.38 to 1.24 \\
\hline & Yes, $\geq 1,088$ tons/life & 121 & 92 & 29 & $<0.01$ & 2.13 & 1.14 to 3.98 \\
\hline \multirow{3}{*}{$\begin{array}{l}\text { Sports with } \\
\text { risk for } \\
\text { unapparent } \\
\text { trauma }\end{array}$} & No (R) & 570 & 342 & 228 & & 1.00 & - \\
\hline & Yes, $<1,440$ hours/life & 81 & 41 & 40 & NS & 0.92 & 0.48 to 1.75 \\
\hline & Yes, $\geq 1,440$ hours/life & 78 & 50 & 28 & $<0.01$ & 2.47 & 1.31 to 4.65 \\
\hline
\end{tabular}

NS, not significant; (R), reference category. 
Coggon and colleagues calculated an OR of $1.7(95 \%$ CI, 1.2 to 2.6) for regular lifting and carrying of loads $>25 \mathrm{~kg}$ (men and women considered in common) [21]. In the study by Seidler and colleagues, lifting and carrying of loads was significantly associated with knee osteoarthritis [20]. The dose-response relationship between lifting and carrying of loads and knee OA was described with an OR of 2.0 ( $95 \% \mathrm{CI}, 1.1$ to 3.6 ) in the exposure group of 630 to $<5,120 \mathrm{~kg}$-hours over life, up to an OR of 2.6 (95\% CI, 1.1 to 6.1 ) in the highest exposure group ( $>37,000 \mathrm{~kg}$-hours over life) in men. Jensen also investigated the correlation between knee OA and lifting and carrying of loads in her review [8]. She concluded that there is moderate evidence of a dose-response relationship between the lifting and carrying of loads and knee OA.

Our results support the current position that there is moderate evidence of a dose-response relationship between the lifting and carrying of loads and symptomatic knee OA.

\section{Symptomatic knee $O A$ and jumping down or climbing stairs or ladders}

In the present study, neither in men nor in women could a correlation between jumping or climbing stairs and symptomatic knee OA be described. McAlindon and colleagues examined a subset of the Framingham Heart Study cohort [22]. They also did not detect effects of climbing stairs. Mounach and colleagues reported in their case-control study that climbing stairs $>50$ steps/day was associated with a decreased risk of knee OA (OR, 0.5; 95\% CI, 0.3 to 0.9) [23]. In contrast, Cooper and colleagues reported an increased OR in people climbing $>10$ flights of stairs per day (OR 2.7, 95\% CI, 1.2 to 6.1) [24]. Sandmark and colleagues described an increased OR (OR, 2.7; 95\% CI, 1.7 to 4.1) for jumping in men, but not in women [25]. In the same study, a slightly increased but predominantly nonsignificant OR was described for climbing stairs in both genders. Manninen and colleagues referred to their results of a case-control study wherein climbing already at a medium level of exposure was associated with an increased risk of knee OA among men (OR $3.1 ; 95 \%$ CI, 1.3 to 7.5 ) [26]. Although in laboratory analyses Sahlström and colleagues identified that jumping down or climbing stairs and ladders revealed a significant increase in movement in the knee compared with normal walking [27], the effect of these exposures on the knee cartilage remains unclear. Our results could not support either of these effects.

\section{Symptomatic knee $O A$ and other work factors}

In the present study, a correlation between symptomatic knee $\mathrm{OA}$ and further work factors (piece-work, time pressure, hand-arm or whole-body vibration, manual handling of heavy tools, working in wetness, coldness, or heat) could not be found. Elsner and colleagues described significant associations between knee $\mathrm{OA}$ and some of the work factors just mentioned [28]. In men, hand-arm vibration (OR, 2.8; 95\% CI, 1.2 to 6.4) as well as working under wet/cold conditions and/or draught (OR, 2.0; 95\% $\mathrm{CI}, 1.2$ to 3.8 ) were associated with knee OA, but not in women. In women, manual handling of heavy tools (OR, 6.1; 95\% CI, 2.0 to 20.1) was associated with knee OA, but not in men. Sandmark and colleagues described a slightly increased but nonsignificant OR for vibration in men, but no effect in women [25]. To conclude, there seems to be low evidence for the effect of additional working factors on the knee, but few studies dealing with these topics are available. Our results do not support the results of Sandmark and colleagues [25] and of Elsner and colleagues [28].

\section{Symptomatic knee OA and individual factors Symptomatic knee OA and body mass index}

Of all the factors observed in the present study, the increase of the BMI correlated strongest in both genders. As stated above, compared with those with normal body weight, an OR up to 12.6 (95\% CI, 4.4 to 35.9) in men with obesity grade II or obesity grade III and up to 17.6 (95\% CI, 4.5 to 69.2 ) in women with obesity grade III was calculated. These findings are in compliance with common literature that describes obesity as a major risk factor in the occurrence of symptomatic knee OA.

Anderson and Felson calculated an OR for overweight (OR, 1.7; 95\% CI, 1.1 to 2.8 ), for obesity grade I (OR, 4.8; $95 \% \mathrm{CI}, 2.8$ to 8.3 ), and for obesity grade II + III (OR, 4.5; $95 \%$ CI, 1.8 to 11.2) compared with normal body weight in men [29]. In women, the OR was also calculated for overweight (OR, 1.9; 95\% CI, 1.2 to 2.9 ), for obesity grade I (OR, 3.9; 95\% CI, 2.6 to 5.7), and for obesity grade II and obesity grade III (OR, 7.4; 95\% CI, 5.2 to 10.5), compared with woman with normal weight.

A recent longitudinal study shows that, compared with subjects with a normal BMI, those who were obese (BMI 30 to $\left.<35 \mathrm{~kg} / \mathrm{m}^{2}\right)$ or very obese $\left(\mathrm{BMI} \geq 35 \mathrm{~kg} / \mathrm{m}^{2}\right)$ were at an increased risk of incident knee OA (relative risk, 2.4 and 3.2, respectively; $P$ for trend $<0.001$ ) [30]. Among others, the relevance of BMI was confirmed by Cooper and colleagues (OR, 3.3; 95\% CI, 1.6 to 6.9 for BMI $\geq 25$ $\mathrm{kg} / \mathrm{m}^{2}$ compared with those with BMI $<25 \mathrm{~kg} / \mathrm{m}^{2}$ among both genders) [31], by Dawson and colleagues (OR, 36.4; $95 \%$ CI, 3.1 to 432.0 for BMI $\geq 25 \mathrm{~kg} / \mathrm{m}^{2}$ compared with those with BMI $<25 \mathrm{~kg} / \mathrm{m}^{2}$ among both genders) [32], and by Liu and colleagues (OR, 10.5; 95\% CI, 7.9 to 14.1 for BMI $\geq 25 \mathrm{~kg} / \mathrm{m}^{2}$ compared with those with BMI $<25 \mathrm{~kg} /$ $\mathrm{m}^{2}$ among both genders) [33].

Hartmann and Seidel examined data from male construction workers [34]. They calculated the OR for overweight (OR, 1.2; 95\% CI, 1.1 to 1.3 ), for obesity grade I (OR, 1.5; 95\% CI, 1.3 to 1.7), for obesity grade II (OR, 1.6; $95 \% \mathrm{CI}, 1.2$ to 2.1 ), and for obesity grade III (OR, 1.8; $95 \%$ 
Table 6: Conditional logistic regression model for men: most parsimonious model

\begin{tabular}{|c|c|c|c|c|c|c|c|}
\hline & Item & $n_{\text {tot }}$ & Cases $(n)$ & Controls (n) & $P$ value & Odds ratio & $\begin{array}{l}95 \% \\
\text { confidence } \\
\text { interval }\end{array}$ \\
\hline \multirow{2}{*}{$\begin{array}{l}\text { Knee OA in } \\
\text { relatives }\end{array}$} & No $(R)$ & 367 & 170 & 197 & & 1.00 & - \\
\hline & Yes & 109 & 76 & 33 & $<0.01$ & 2.37 & 1.41 to 3.98 \\
\hline \multirow{4}{*}{$\begin{array}{l}\text { Body mass } \\
\text { index }\end{array}$} & 18.5 to $<25 \mathrm{~kg} / \mathrm{m}^{2}(\mathrm{R})$ & 157 & 48 & 109 & & 1.00 & - \\
\hline & $\geq 25$ to $<30 \mathrm{~kg} / \mathrm{m}^{2}$ & 240 & 133 & 107 & $<0.001$ & 2.26 & 1.43 to 3.57 \\
\hline & $\geq 30$ to $<35 \mathrm{~kg} / \mathrm{m}^{2}$ & 128 & 84 & 44 & $<0.001$ & 4.00 & 2.30 to 6.94 \\
\hline & $\geq 35 \mathrm{~kg} / \mathrm{m}^{2}$ & 40 & 35 & 5 & $<0.001$ & 12.56 & $\begin{array}{l}4.40 \text { to } \\
36.86\end{array}$ \\
\hline \multirow{4}{*}{$\begin{array}{l}\text { Occupation } \\
\text { :kneeling or } \\
\text { squatting }\end{array}$} & No $(R)$ & 272 & 128 & 144 & & 1.00 & - \\
\hline & Yes, $<3,574$ hours/life & 94 & 48 & 46 & NS & 1.70 & 0.96 to 3.00 \\
\hline & $\begin{array}{l}\text { Yes, } 3,574 \text { to } 12,244 \\
\text { hours/life }\end{array}$ & 94 & 55 & 39 & $<0.01$ & 2.16 & 1.24 to 3.77 \\
\hline & Yes, $>12,244$ hours/life & 94 & 61 & 33 & $<0.01$ & 2.47 & 1.41 to 4.32 \\
\hline \multirow{3}{*}{$\begin{array}{l}\text { Sports with } \\
\text { risk for } \\
\text { unapparent } \\
\text { trauma }\end{array}$} & No $(R)$ & 218 & 109 & 109 & & 1.00 & - \\
\hline & Yes, $<3,232$ hours/life & 168 & 82 & 86 & NS & 1.57 & 0.98 to 2.52 \\
\hline & Yes, $\geq 3,232$ hours/life & 168 & 104 & 64 & $<0.01$ & 2.58 & 1.59 to 4.17 \\
\hline
\end{tabular}

NS, not significant; (R), reference category.

CI, 1.0 to 3.0) compared with men of normal weight. Liu and colleagues further reported that about $69 \%$ of the knee joint replacements in their study sample were to be assigned to overweight causes [33].

According to the results of Wang and colleagues [35], the risk of primary knee and hip joint replacement due to OA relates to both adipose mass and central adiposity. This relationship suggests that both biomechanical and metabolic mechanisms associated with obesity contribute to the risk of joint replacement, with stronger evidence at the knee rather than at the hip.

Our results support these existing results. We could clearly find a strong correlation between increasing BMI and symptomatic knee OA.

\section{Symptomatic knee $O A$ and malalignment of the tibiofemoral joint}

In the data from the present study, the existence of malalignment of the tibiofemoral joint was associated with symptomatic knee OA in women only (OR, 11.5, 95\% CI, 4.7 to 28.7 compared with women without malalignment of the knee).

Malalignment of the knee has rarely found consideration in the relevant epidemiologic literature [11].
Schouten and colleagues published their results of a 12year follow-up study in 1992 [36]. Besides other factors, previous malalignment of the tibiofemoral joint (OR, 5.1; 95\% CI, 1.1 to 23.1 compared with people without malalignments) was determined as a prognostic factor for development of knee OA. Greinemann wrote in his 1983 study among mine foremen that slight malalignment of the tibiofemoral joint did not promote knee OA [37]. A high position of the patella, however, might be an aggressive prearthritic deformity according to the results of that study. Unfortunately, the position of the patella was not assessed in the present study.

Our results support the findings of the current review by Tanamas and colleagues [11], in which malalignment of the tibiofemoral joint was found to be an independent risk factor for the progression of symptomatic knee OA. Symptomatic knee $O A$ and genetic predisposition In both genders, knee OA within parents, brothers, or sisters was a significant predictor for symptomatic knee OA in the investigated person. The OR was 2.2 (95\% CI, 1.4 to 3.4 ) in women and 2.4 (95\% CI, 1.4 to 4.0$)$ in men.

Cooper and colleagues described an OR for the heredity of knee OA of 2.7 (95\% CI, 1.3 to 5.5) for both genders 
combined [24]. The influence of genetic factors for the development of knee OA was the focus of the work group of Spector and colleagues in several studies. In 1996 they published a study among female twins in which they prove a genetic effect for knee and hand OA [38]. The intraclass correlation of a radiographic OA score in identical pairs was 0.64 compared with nonidentical pairs (0.38). In 2004 Spector and MacGregor summarised their findings about the influence of genetic factors of $\mathrm{OA}$ derived from classic twin studies [6]. They indicated that the influence of genetic factors was 39 to $65 \%$ in knee/ hand OA, $60 \%$ in hip OA, and 70\% in spine OA. According to the authors, therefore, about one-half of OA can be explained by genetic factors [6].

In our study, the assessment of genetic influences was conducted only by the question about knee OA within parents, brothers, or sisters. As described above, the OR clearly increased for both men and women in connection to genetic predisposition. Our results are in compliance with the results of the authors mentioned above.

\section{Symptomatic knee $O A$ and smoking}

The factor of smoking (here measured in package-years) was negatively associated with symptomatic knee OA in women (smoking $>20$ package-years). This phenomenon has been discussed several times in other studies.

Felson and colleagues described this phenomenon in an overview article [39] after they detected the negative association between smoking and knee OA when evaluating two large datasets derived from the First National Health and Nutrition Examination Survey (NHANES I) [29] and from the Framingham Heart Study [2]. It appears that smoking or some unidentified factor correlated with smoking modestly protects against the development of knee OA. As a possible explanation, Gullahorn and colleagues reported that, according to their study results, nicotine upregulates glycosaminoglycan and collagen synthetic activity of articular chondrocytes [40]. The findings about the correlation between smoking and knee OA were summarised by Elloumi and Kallel [41]. They concluded that smoking would have a modest protective effect against the development of OA. This protective effect would be widely supported by the anabolic activity that nicotine carries on the chondrocytes of the articular cartilage. Given the dangers associated with nicotine and smoking, however, one cannot recommend tobacco as a prevention factor for OA [41]. Our results are in compliance with the results of these authors.

\section{Symptomatic knee $O A$ and sports}

In our study when looking at sports with a risk of unapparent knee trauma, cumulative sports (addition of hours over life of all these kinds of sports) was observed to be a relevant factor for symptomatic knee OA. The OR was 2.5 (95\% CI, 1.3 to 4.6) in women performing $\geq 1,440$ hours over life and was 2.6 (95\% CI, 1.6 to 4.2$)$ within men having performed $\geq 3,232$ hours over life, compared with persons without any sporting activities.

Participation in physical activity is widely accepted to be associated with physical, psychological, and social benefits [42]. In the literature, few studies could be identified that investigated the correlation between sports history and the development of knee OA. In a review by Gross and Marti, the evidence of the correlation between $\mathrm{OA}$ and sports was described as moderate [5]. They concluded that very intensive sports exercise can lead to a low-grade increase in the risk for hip and knee OA (ball and strength sports in particular). In very active runners, the risk of $\mathrm{OA}$ also increases. The risk of $\mathrm{OA}$ at the weight-bearing joints (hip and knee) might be increased by extremely intensive and long-time sports activity, but might not be predominant in the majority of the population engaging in sports, since the amount of sports activity is lower. A recent review [9] detected that some studies had reported an association between physical activity and a risk for knee OA [43-45], and that other studies had shown physical activity may have no effect $[46,47]$ or may even protect the knee joint from degenerative changes $[48,49]$.

In contrast to our results, Manninen and colleagues referred to a comparative analysis of different kinds of sports and knee OA in a case-control study [50]. The OR for knee arthroplasty decreased to 0.9 (95\% CI, 0.3 to 2.6 ) in men with a low number of cumulative exercise hours and to 0.4 (0.1 to 0.95$)$ in those with a high number of cumulative exercise hours, with a history of no regular physical exercise as the reference. For the women, the corresponding ORs were 0.6 (0.3 to 0.93$)$ and 0.6 (0.3 to 0.98 ). The authors concluded that recreational physical exercise was associated with a decrease in the risk of knee OA [50]. Urquhart and colleagues concluded that certain types of exercise had different effects on different people [9]. Rather than a uniform approach to the implementation of physical activity, individually tailored exercise programmes were needed to allow exercise to be carried out safely.

On the basis of our results, we support the necessity for further investigations on the relationship between physical exercise and symptomatic knee OA.

\section{Strengths and weaknesses of the present study Strengths of the study}

The principle strength of the present study lies in the high power of the dataset. Another strength is the extensive anamnesis, incorporating occupational factors as well as individual factors and leisure-time activities. Additionally, compared with other case-control studies in Germany [51], the response rate is quite high $(73.2 \%$ in cases and $65.4 \%$ in controls). Compared with interna- 
tional studies, however, the response rate is moderate and nonresponse bias may have influenced the results.

\section{Weaknesses of the study}

Characteristics of the study sample Points of concern are the unequal number of and the unequal age distribution of cases and controls. Owing to this unequal distribution, age-stratified evaluations were carried out to minimise this potential bias. Possible effects of occupational tasks indicated rarely may have been missed due to the fact that the initially calculated sample size could not be reached.

Exposure assessment by self-report According to the study design, exposure assessment had to be assessed retrospectively by self-report - recall bias may therefore occur. People affected by pain in the knee may have overestimated the influencing factors (for example, kneeling or having pain already in childhood). We tried to deflect respondents from the topic of knee OA during recruitment and survey. Cases and controls were told to participate in a general study about the musculoskeletal system; however, cases might have overestimated relevant exposures. Besides, data from the literature suggest that straining activities (such as kneeling) seem to be overestimated in retrospective exposure assessment by selfreport. The overestimation with regard to kneeling activities reached up to 30 to $45 \%$ on comparing observation and self-reporting immediately after the work shift $[52,53]$. Since the exposure requested in the present study dated back many years, the overestimation might be even higher. The amount of this recall bias could not be determined, however, as objective data (for example, observation or exposure measurements) on the participants' former activities were not available.

Selection of cases The injury of joint structures, such as the menisci or cruciate ligaments, is a known risk factor for the development of knee OA $[9,54]$. Meniscal injuries are the most common injuries to the knee [55]. In our study, we strictly excluded all cases that reported previous knee trauma. Yet undetected or unremembered knee injuries might have been prevalent in cases and may have biased the results.

Suitability of the control group The selection of controls was discussed with the advisory board of the present study during development of the study design. Generally, a primarily defined study base is preferred in case-control studies. In Germany, research groups often make use of the database of the public registry office of individual cities in order to recruit population-based controls. With this database, a nearly unbiased sample of a defined region can theoretically be obtained. Yet this method of recruitment can also be disadvantageous, since response rates often turn out to be very low [51]. In addition, controls may return only incomplete questionnaires as their motivation for participation may be lower than in the case group. The data from controls may thus not only be unrepresentative for the general population but also less informative than those of the case group.

Cases were selected from hospitals in the study. The use of this secondary study base was necessary as register data regarding patients with knee OA are not available in Germany. Controls were consistently also collected as hospital-based, addressing the accident surgery wards. The setting for recruitment was therefore the same for both cases and controls. This is crucial, as similarity between recruiting cases and controls is the most important factor [56].

The surgery in Germany is free of charge and patients choose their hospitals, so there should be no bias in selection of the hospitals. The patients were personally contacted by their treating physician. We assumed that this approach may have lead to an essentially higher response rate and higher quality of data than in controls from the public registry database.

The degree to which the hospital control sample is representative of the general population was assessed with respect to occupation, general health status (prevalence of myocardial infarction, apoplexy, hypertension, diabetes, cancer and concussion), education, and smoking habits using databases (the Federal Health Survey 1998 (BGS '98) [57], employment data of the regional Federal Employment Office, and a community-based health study - the Dortmunder Gesundheitsstudie [58] - which was run simultaneously in the same geographical region by other research institutes).

As cases and controls were addressed consecutively and in retrospect, the response rate and general health status of the subgroups were compared in order to control for any bias with respect to the recruitment strategy.

In all of these comparisons, no relevant differences were covered - the results should therefore be generalizable to the general population in the region observed.

\section{Conclusions}

Occupational and nonoccupational risk factors play an important role in the aetiology of symptomatic knee OA. Against the background of a wide variety of discussed risk factors for knee OA, the ArGon study provided the possibility to analyse a large amount of these possible different predictors in multivariable conditional analyses for men and women. In women, for the first time, a dose-response relationship between different predictors and the occurrence of symptomatic knee OA could be described. In both men and women, the relevance of occupational factors as well as nonoccupational and constitutional predictors could be shown.

It is likely that, as in other chronic diseases, these risk factors are either synergistic or additive, and each has a graded relationship to OA risk (for example, the more 
obese, the higher the risk). Those at highest risk have more than one risk factor [59]. Among the risk factors taken into account in the present study, only a few are modifiable. According to the results of our study, prevention measures in the occupational field should focus on the reduction of kneeling activities as well as the reduction of lifting and carrying. Aside from the aspects of working conditions, prevention should focus on the reduction of obesity. According to the results of Niu and colleagues, obesity was a risk factor for the incidence of but not for the progression of knee OA [30]. These results underline the importance of the early prevention and reduction of obesity.

The importance of preventive behavioural approaches such as weight management and workplaces designed to limit joint overuse was also postulated after analysing the data of the First National Health Survey in Germany [60]. Jensen and Friche reported on an interventional study where information, education and training in the use of new tools and working methods for the purpose of reducing knee strain and knee complaints were implemented in floor layers [61]. The evaluation after 2 years showed that $38 \%$ used the new working methods weekly or daily, compared with 37\% 3 months after the courses and 10\% before. Among controls, only $16 \%$ had used the new working methods weekly or daily. The risk of knee complaints was more than double among floor layers who had used the new working methods for less than 1 year, compared with those who had used them more. More welldesigned intervention studies on the effectiveness of tools and working methods for the purpose of reducing kneestraining activities are needed. In addition, the implementation of knee-strengthening exercises in worksite health-promotion programmes should be evaluated.

\section{Abbreviations}

BMl: body mass index; $\mathrm{Cl}$ : confidence interval; OA: osteoarthritis; OR: odds ratio.

\section{Competing interests}

The authors declare that they have no competing interests.

\section{Authors' contributions}

AK, HG, BB, and MAR conceived and designed the study, AK and MAR prepared the manuscript. In addition, EQP, WC, LVVE, MS, and AD were involved in the execution of the study and the writing of this manuscript. MN gave assistance in epidemiological issues and performed parts of the statistical analyses. FL represents the funding body, initiated the study, and was closely involved in the planning and development of the study design. All authors read and approved the final manuscript.

\section{Acknowledgements}

The present study was funded by the German Federal Institute for Occupational Safety and Health (BAuA) (project reference number F2096). The work of the Institute of Occupational and Social Medicine Tübingen is supported by an unrestricted grant of the employers' association of the metal and electric industry Baden-Württemberg (Südwestmetall). During the development process of the questionnaire, existing questionnaires were taken into account. The authors would like to thank Prof. David Coggon (Southampton University, UK), PhD Dr Héléne Sandmark (Örebro University, Sweden), and PD Dr Andreas Seidler (Federal Institute for Occupational Safety and Health, Berlin, Germany), who kindly sent us their questionnaires used in former studies. Furthermore, the authors would like to thank Prof. Dr Andreas Nieß (Tübingen University Hospital, Germany) for the discussion of the impact of sports on the knee, Zeynep Karabaczak (Institute ASER, Wuppertal, Germany) for the execution of the telephone interviews, and Peter Lenco for the language check of the manuscript. They would also like to thank Dr Philip Helm, Dr Ted Böhmer, Dr Andreas Wafeisade, Dr Vera Schmitz-Greven, Dr Tilo Tinschmann and Regina Langen from the Department of Trauma and Orthopaedic Surgery, Hospital Cologne Merheim, Germany for their assistance in data collection.

\section{Author Details}

${ }^{1}$ Institute of Occupational Health, Safety and Ergonomics (ASER) at the University of Wuppertal, Corneliusstraße 31, 42329 Wuppertal, Germany, 2Freiburg Research Centre for Occupational and Social Medicine (FFAS), Bertoldstraße 27, 79098 Freiburg, Germany, ${ }^{3}$ Federal Institute for Occupational Safety and Health, Noeldnerstraße 40-42, 10317 Berlin, Germany, ${ }^{4}$ Centre for Orthopaedics and Rheumatology, Clinic for General Orthopaedics, Sankt Josef Hospital, Bergstraße 6-12, 42105 Wuppertal, Germany, 5Department of Trauma and Orthopedic Surgery, University of Witten/Herdecke, HELIOS Hospital Wuppertal, Heusnerstraße 40, 42283 Wuppertal, Germany, ${ }^{6}$ Department of Trauma and Orthopaedic Surgery, University of Witten/Herdecke, Hospital Cologne Merheim, Ostmerheimerstraße 200, 51109 Cologne, Germany, 7 Department of Occupational Health and Environmental Medicine, Institute of General Practice and Family Medicine, University of Witten/Herdecke, AlfredHerrhausen-Straße 50, 58448 Witten, Germany and ${ }^{8}$ Institute of Occupational and Social Medicine, University Hospital of Tuebingen, Wilhelmstraße 27, 72074 Tuebingen, Germany

Received: 21 July 2009 Revised: 29 January 2010

Accepted: 14 May 2010 Published: 14 May 2010

\section{References}

1. SuGA - Sicherheit und Gesundheit bei der Arbeit 2007 [http:// www.baua.de/de/Publikationen/Fachbeitraege/Suga-2007/

2. Felson DT, Hannan MT, Naimark A, Berkeley J, Gordon G, Wilson PW, Anderson J: Occupational physical demands, knee bending, and knee osteoarthritis: results from the Framingham Study. J Rheumatol 1991 , 18:1587-1592

3. Jensen $L K$, Eenberg W: Occupation as a risk factor for knee disorders. Scand J Work Environ Health 1996, 22:165-175.

4. Maetzel A, Makela M, Hawker G, Bombardier C: Osteoarthritis of the hip and knee and mechanical occupational exposure - a systematic overview of the evidence. J Rheumatol 1997, 24:1599-1607.

5. Gross P, Marti B: Sportliche Aktivität und Arthrose-Risiko [Exercise, sport, and risk of osteoarthrosis]. Schweiz Med Wochenschr 1997, 127:967-977.

6. Spector TD, MacGregor AJ: Risk factors for osteoarthritis: genetics. Osteoarthritis Cartilage 2004, 12 Suppl A:S39-S44.

7. McMillan G, Nichols L: Osteoarthritis and meniscus disorders of the knee as occupational diseases of miners. Occup Environ Med 2005, 62:567-575

8. Jensen LK: Knee osteoarthritis: influence of work involving heavy lifting, kneeling, climbing stairs or ladders, or kneeling/squatting combined with heavy lifting. Occup Environ Med 2008, 65:72-89.

9. Urquhart DM, Soufan C, Teichtahl AJ, Wluka AE, Hanna F, Cicuttini FM: Factors that may mediate the relationship between physical activity and the risk for developing knee osteoarthritis [review]. Arthritis Res Ther 2008, 10:203.

10. Felson DT: Developments in the clinical understanding of osteoarthritis [review]. Arthritis Res Ther 2009, 11:203.

11. Tanamas S, Hanna FS, Cicuttini FM, Wluka AE, Berry P, Urquhart DM: Does knee malalignment increase the risk of development and progression of knee osteoarthritis? A systematic review [review]. Arthritis Rheum 2009, 61:459-467.

12. Klussmann A, Gebhardt H, Liebers F, von Engelhardt LV, Dávid A, Bouillon $B$, Rieger MA: Individual and occupational risk factors for knee osteoarthritis - study protocol of a case control study. BMC Musculoskelet Disord 2008, 9:26.

13. Kellgren JH, Lawrence JS: Atlas of Standard Radiographs: The Epidemiology of Chronic Rheumatism Volume 2. Oxford: Blackwell; 1963. 
14. Outerbridge RE: The etiology of chondromalacia patellae. J Bone Joint Surg Br 1961, 43-B:752-757.

15. EpiManager Software [http://www.baua.de/de/Informationen-fuer-diePraxis/Handlungshilfen-und-Praxisbeispiele/EpiManager.html]

16. Hosmer DW, Lemeshow S: Applied Logistic Regression Hoboken, New Jersey: John Wiley \& Sons; 1989.

17. WHO: BMI classification [http://www.who.int/bmi/ index.jsp?introPage=intro $3 . \mathrm{html}]$

18. Jensen LK: Knee-straining work activities, self-reported knee disorders and radiographically determined knee osteoarthritis. Scand J Work Environ Health 2005, 31:68-74.

19. D'Souza JC, Werner RA, Keyserling WM, Gillespie B, Rabourn R, Ulin S, Franzblau A: Analysis of the Third National Health and Nutrition Examination Survey (NHANES III) using expert ratings of job categories. Am J Ind Med 2008, 51:37-46

20. Seidler A, Bolm-Audorff U, Abolmaali N, Elsner G, Knee Osteoarthritis Study Group: The role of cummulative physical work load in symptomatic knee osteoarthritis - a case control study in Germany. $J$ Occup Med Toxicol 2008, 3:14.

21. Coggon D, Croft P, Kellingray S, Barrett D, McLaren M, Cooper C: Occupational physical activities and osteoarthritis of the knee. Arthritis Rheum 2000, 43:1443-1449.

22. McAlindon TE, Wilson PW, Aliabadi P, Weissman B, Felson DT: Level of physical activity and the risk of radiographic and symptomatic knee osteoarthritis in the elderly: the Framingham study. Am J Med 1999, 106:151-157.

23. Mounach A, Nouijai A, Ghozlani I, Ghazi M, Achemlal L, Bezza A, El Maghraoui A: Risk factors for knee osteoarthritis in Morocco. A case control study. Clin Rheumatol 2008, 27:323-326.

24. Cooper C, McAlindon T, Coggon D, Egger P, Dieppe P: Occupational activity and osteoarthritis of the knee. Ann Rheum Dis 1994, 53:90-93.

25. Sandmark H, Hogstedt C, Vingård E: Primary osteoarthrosis of the knee in men and women as a result of lifelong physical load from work. Scand J Work Environ Health 2000, 26:20-25.

26. Manninen P, Heliövaara M, Riihimäki H, Suomalainen O: Physical workload and the risk of severe knee osteoarthritis. Scand J Work Environ Health 2002, 28:25-32.

27. Sahlström A, Lanshammar H, Adalberth G: Knee joint moments in workrelated situations. Ergonomics 1995, 38:1352-1359.

28. Elsner G, Nienhaus A, Beck W: Kniegelenksarthrose und arbeitsbedingte Faktoren [Knee joint arthroses and work-related factors]. Soz Präventivmed 1996, 41:98-106.

29. Anderson JJ, Felson DT: Factors associated with osteoarthritis of the knee in the first national Health and Nutrition Examination Survey (HANES I). Evidence for an association with overweight, race, and physical demands of work. Am J Epidemiol 1988, 128:179-189.

30. Niu J, Zhang YQ, Torner J, Nevitt M, Lewis CE, Aliabadi P, Sack B, Clancy M, Sharma $L$, Felson DT: Is obesity a risk factor for progressive radiographic knee osteoarthritis? Arthritis Rheum 2009, 61:329-335.

31. Cooper C, McAlindon T, Snow S, Vines K, Young P, Kirwan J, Dieppe P: Mechanical and constitutional risk factors for symptomatic knee osteoarthritis: differences between medial tibiofemoral and patellofemoral disease. J Rheumatol 1994, 21:307-313.

32. Dawson J, Juszczak E, Thorogood M, Marks SA, Dodd C, Fitzpatrick R: An investigation of risk factors for symptomatic osteoarthritis of the knee in women. J Epidemiol Community Health 2003, 57:823-830.

33. Liu B, Balkwill A, Banks E, Cooper C, Green J, Beral V: Relationship of height, weight and body mass index to the risk of hip and knee replacements in middle-aged women. Rheumatology (Oxford) 2007 46:861-867.

34. Hartmann B, Seidel D: Das Kniegelenk unter den körperlichen Belastungen der Bauwirtschaft [The knee joint under the physical stresses of the construction industry]. Zbl Arbeitsmed 2003, 53:428-441.

35. Wang Y, Simpson JA, Wluka AE, Teichtahl AJ, English DR, Giles GG, Graves $S$, Cicuttini FM: Relationship between body adiposity measures and risk of primary knee and hip replacement for osteoarthritis: a prospective cohort study. Arthritis Res Ther 2009, 11:R31.

36. Schouten JS, Ouweland FA van den, Valkenburg HA: A 12 year follow up study in the general population on prognostic factors of cartilage loss in osteoarthritis of the knee. Ann Rheum Dis 1992, 51:932-937.

37. Greinemann H: Prädestinieren Kniescheibenhochstand, Knie- und Kniescheibenfehlformen sowie Beinachsenfehlstellungen bei kniebelastenden
Berufen zu vorzeitigem Verschleiß? [Do Raised Knee-caps, Knee and Knee-cap Deformation as well as Leg Axial Deformation in Knee-straining Professions Predestinate Premature Wear and Tear?] Forschungsbericht der Bundesanstalt für Arbeitsschutz Number 362 Bremerhaven: Wirtschaftsverlag NW; 1983.

38. Spector TD, Cicuttini F, Baker J, Loughlin J, Hart D: Genetic influences on osteoarthritis in women: a twin study. BMJ 1996, 312:940-943.

39. Felson DT, Anderson JJ, Naimark A, Hannan MT, Kannel WB, Meenan RF: Does smoking protect against osteoarthritis? Arthritis Rheum 1989, 32:166-172.

40. Gullahorn L, Lippiello L, Karpman R: Smoking and osteoarthritis: differential effect of nicotine on human chondrocyte glycosaminoglycan and collagen synthesis. Osteoarthritis Cartilage 2005, 13:942-943

41. Elloumi M, Kallel MH: Which relationship does osteoarthritis share with smoking? Osteoarthritis Cartilage 2007, 15:1097-1098.

42. Bauman AE: Updating the evidence that physical activity is good for health: an epidemiological review 2000-2003. J Sci Med Sport 2004, 7:6-19.

43. Spector TD, Harris PA, Hart DJ, Cicuttini FM, Nandra D, Etherington J, Wolman RL, Doyle DV: Risk of osteoarthritis associated with long-term weight-bearing sports: a radiologic survey of the hips and knees in female ex-athletes and population controls. Arthritis Rheum 1996 39:988-995.

44. Cheng Y, Macera CA, Davis DR, Aiinsworth BE, Troped PJ, Blair SN: Physical activity and self-reported, physician-diagnosed osteoarthritis: is physical activity a risk factor? J Clin Epidemiol 2000, 53:315-322.

45. Szoeke C, Dennerstein L, Guthrie J, Clark M, Cicuttini F: The relationship between prospectively assessed body weight and physical activity and prevalence of radiological knee osteoarthritis in postmenopausal women. J Rheumatol 2006, 33:1835-1840.

46. Hootman JM, Macera CA, Helmick CG, Blair SN: Influence of physical activity-related joint stress on the risk of selfreported hip/knee osteoarthritis: a new method to quantify physical activity. Prev Med 2003, 36:636-644

47. Felson DT: The epidemiology of knee osteoarthritis: results from the Framingham Osteoarthritis Study. Semin Arthritis Rheum 1990, 20:42-50.

48. White JA, Wright V, Hudson AM: Relationships between habitual physical activity and osteoarthrosis in ageing women. Public Health 1993, 107:459-470.

49. Rogers LQ, Macera CA, Hootman JM, Ainsworth BE, Blairi SN: The association between joint stress from physical activity and selfreported osteoarthritis: an analysis of the Cooper Clinic data. Osteoarthritis Cartilage 2002, 10:617-622.

50. Manninen P, Riihimaki H, Heliövaara M, Suomalainen O: Physical exercise and risk of severe knee osteoarthritis requiring arthroplasty. Rheumatology 2001, 40:432-437.

51. Latza U, Stang A, Bergmann M, Kroke A, Sauer S, Holle R, Kamtsiuris P, Terschueren C, Hoffmann W: Zum Problem der Response in epidemiologischen Studien in Deutschland (Teil I) [The problem of response in epidemiological studies in Germany (part I)]. Gesundheitswesen 2004, 66:326-336.

52. Bolm-Audorff U, Kronen A, Hofman M, Wunderlich A: Häufigkeit von Kniegelenksbelastungen in ausgewählten Berufsgruppen [Frequency of knee straining activities in selected occupational groups]. In Dokumentation der 47 Mainz: Wissenschaftlichen Jahrestagung der Deutschen Gesellschaft für Arbeitsmedizin und Umweltmedizin; 2007:224-228

53. Klussmann A, Gebhardt H, Rieger MA: Körperliche Belastungen und Beschwerden bei Beschäftigten in einem Kanal- und Rohrnetzbetrieb [Physical loads and symptoms among employees in sewerage]. In Dokumentation zum 54. Kongress der Gesellschaft für Arbeitswissenschaft Edited by: Gesellschaft für Arbeitswissenschaft. München: GfA-Press: 2008:621-624

54. Felson D, Niu J, Clancy M, Sack B, Aliabadi P, Zhang Y: Effect of recreational physical activities on the development of knee osteoarthritis in older adults of different weights: the Framingham Study. Arthritis Rheum 2007, 57:6-12.

55. Renström P, Johnson RJ: Anatomy and biomechanics of the menisci. Clin Sports Med 1990, 9:523-538.

56. Grimes DA, Schulz KF: Compared to what? Finding controls for casecontrol studies. Lancet 2005, 365:1429-1433. 
57. Public Use File BGS98: Bundes-Gesundheitssurvey 1998 Berlin: Robert KochInstitut; 2000

58. Völzke H, Neuhauser H, Moebus S, Baumert J, Berger K, Stang A, Ellert UI, Werner A, Döring A: Rauchen: Regionale Unterschiede in Deutschland [Regional disparties in smoking among adults in Germany]. Deutsches Ärzteblatt 2006, 103:A2784-A2790.

59. Felson DT, Zhang Y: An update on the epidemiology of knee and hip osteoarthritis with a view to prevention. Arthritis Rheum 1998, 41:1343-1355.

60. Schneider S, Schmitt G, Mau H, Schmitt H, Sabo D, Richter W: Prävalenz und Korrelate der Osteoarthrose in der BRD - Repräsentative Ergebnisse des ersten Bundesgesundheitssurvey [Prevalence and correlates of osteoarthritis in Germany - representative data from the First National Health Survey]. Orthopade 2005, 34:782-790.

61. Jensen $L K$, Friche $C$ : Effects of training to implement new working methods to reduce knee strain in floor layers. A two-year follow-up. Occup Environ Med 2008, 65:20-27.

doi: 10.1186/ar3015

Cite this article as: Klussmann et al., Individual and occupational risk factors for knee osteoarthritis: results of a case-control study in Germany Arthritis Research \& Therapy 2010, 12:R88

Submit your next manuscript to BioMed Central and take full advantage of:

- Convenient online submission

- Thorough peer review

- No space constraints or color figure charges

- Immediate publication on acceptance

- Inclusion in PubMed, CAS, Scopus and Google Scholar

- Research which is freely available for redistribution

Submit your manuscript at www.biomedcentral.com/submit
C) Biomed Central 